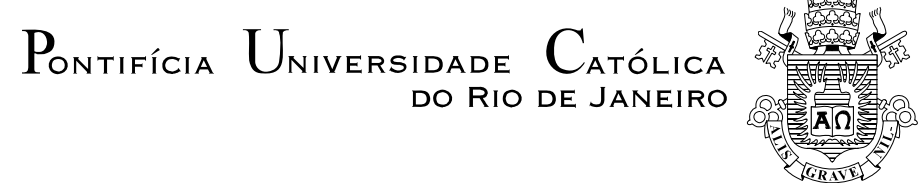

Breno Gomide Braga

Educação, Experiência e o Hiato Salarial entre o Setor Público e Privado no Brasil

Dissertação de Mestrado

Dissertação apresentada como requisito parcial para obtenção do título de Mestre pelo Programa de PósGraduação em Economia da PUC-Rio.

Orientadores: Prof.Sergio Firpo Prof. Gustavo Gonzaga

Rio de Janeiro

Março de 2008 


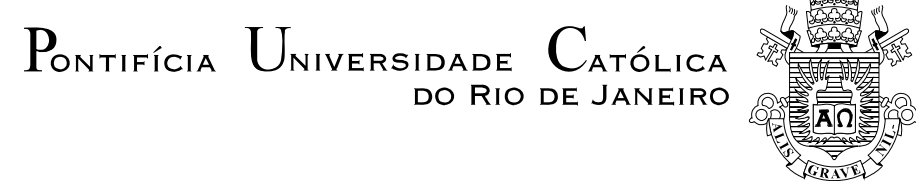

Breno Gomide Braga

\section{Educação, Experiência e o Hiato Salarial entre o Setor Público e Privado no Brasil}

Dissertação apresentada como requisito parcial para obtenção do título de Mestre pelo Programa de PósGraduação em Economia da PUC-Rio. Aprovada pela Comissão Examinadora abaixo assinada.

Prof. Sergio Firpo

Orientador

PUC - Rio

Prof. Gustavo Gonzaga

Co-Orientador

PUC - Rio

Prof. Juliano Assunção

PUC - Rio

Prof. Miguel Foguel

IPEA

Prof. Nizar Messari

Coordenador(a) Setorial do Centro de Ciências Sociais - PUC-Rio

Rio de Janeiro, 31 de março de 2008 
Todos os direitos reservados. É proibida a reprodução total ou parcial do trabalho sem autorização da universidade, do autor e do orientador.

\section{Breno Gomide Braga}

Graduou-se em Ciências Econômicas pela Universidade Federal do Rio de Janeiro (UFRJ) em 2005. Cursou o Mestrado em Economia na PUC-Rio entre 2006 e 2007. Atualmente é candidato ao título de Ph.D em Economia pela University of Michigan.

Ficha Catalográfica

Educação, Experiência e o Hiato Salarial entre o Setor Público e Privado no Brasil / Breno Gomide Braga ; orientadores: Sergio Firpo, Gustavo Gonzaga. 2008.

48 f. ; $30 \mathrm{~cm}$

Dissertação (Mestrado em Economia)-Pontifícia Universidade Católica do Rio de Janeiro, Rio de Janeiro, 2008.

Inclui bibliografia

1. Economia - Teses. 2. Diferencial de rendimentos. 3. Aposentadoria. 4. Setor público. I. Firpo, Sergio Pinheiro. II. Gonzaga, Gustavo. III. Pontifícia Universidade Católica do Rio de Janeiro. Departamento de Economia. IV. Título.

CDD: 330 


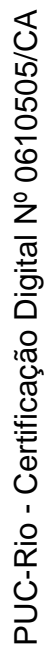

À minha família 


\section{Agradecimentos}

A Capes pelo apoio financeiro para realização do Mestrado.

Aos professores e funcionários da PUC-Rio, por manterem um centro de excelência de ensino de Economia onde tive o privilégio de estudar.

Aos meus colegas de Mestrado, com os quais aprendi muito nos últimos anos.

Aos participantes dos seminários do XXXV Encontro Nacional de Economia (ANPEC) e do IPEA-Rio pelos comentários sobre a versão preliminar da dissertação.

Aos membros da banca examinadora, professores Juliano Assunção e Miguel Foguel, pelas criticas e sugestões.

Aos orientadores Sergio Firpo e Gustavo Gonzaga pela constante disponibilidade em discutir este trabalho. 
A minha irmã, pela alegria e amizade.

Aos meus avós, tios e tias, pelo apoio e interesse.

Aos meus pais, pelo amor e compreensão de ter por dois anos adicionais um filho estudante em casa. 


\section{Resumo}

Braga, Breno Gomide; Firpo, Sergio (Orientador); Gonzaga, Gustavo (Orientador). Educação, Experiência e o Hiato Salarial entre o Setor Público e Privado no Brasil Rio de Janeiro, 2008. 48p. Dissertação de Mestrado - Departamento de Economia, Pontifícia Universidade Católica do Rio de Janeiro.

Este trabalho tem como objetivo investigar os determinantes do diferencial de rendimentos público-privado para diferentes níveis de escolaridade dos trabalhadores no Brasil. Primeiramente, utilizando o rendimento do trabalho principal como variável de interesse, é estimado um hiato de rendimentos bastante favorável ao setor público para trabalhadores com baixa escolaridade. Já para trabalhadores mais qualificados, o hiato tende a desaparecer ou mesmo a tornar-se favorável ao setor privado. Adicionalmente, de maneira a considerar os diferentes regimes de aposentadoria vigentes no país, é definida a variável Valor Presente do Contrato de Trabalho (VPCT) como medida dos rendimentos dos indivíduos ao longo da vida. Diferentemente do resultado encontrado utilizando o rendimento do trabalho, é verificado que o diferencial do VPCT é favorável ao setor público mesmo para trabalhadores com elevados níveis de escolaridade.

\section{Palavras-chave}

Diferencial de Rendimentos; Aposentadoria; Setor Público. 


\section{Abstract}

Braga, Breno Gomide; Firpo, Sergio (Advisor); Gonzaga, Gustavo (Advisor). Education and the Public-Private Earning Gap in Brazil. Rio de Janeiro, 2008. 48p. M.A. Dissertation - Departamento de Economia, Pontifícia Universidade Católica do Rio de Janeiro.

This dissertation studies the determinants of the public-private wage gap for different levels of schooling of Brazilian workers. Firstly, using the current wage as the variable of interest, it is estimated wage gap favorable to the less educated workers from the public sector. On the other hand, for workers with higher qualification the wage gap disappears or becomes favorable to the private sector. Further, we considerate the different regimes of retirement in Brazil by creating the variable Present Value of Work Contract (PVWC). This variable is a measure of the life time earnings for each individual of our database. Different from the results of the current wage, we found that the PVWC gap is favorable to the public sector even for the most educated group of workers.

\section{Keywords}

Wage Gap; Retirement; Public Sector. 


\section{Sumário}

1 Introdução 12

2 Base de Dados 16

3 Metodologia $\quad 22$

3.1. Valor Presente do Contrato de Trabalho 25

4 Resultados $\quad 28$

4.1. Estimações com Logaritmo do Rendimento do Trabalho Principal $\begin{array}{ll}\text { Padronizado } & 28\end{array}$

4.1.1. Diferencial de Rendimentos Padronizado Público-Privado com Controles $\quad 28$

4.1.2. Diferencial de Rendimentos Padronizado Público-Privado por Nível de Escolaridade

4.1.3. Diferencial de Rendimentos Padronizado Público-Privado e Ocupação

4.1.4. Diferencial de Rendimentos Público-Privado e Interações entre Escolaridade e Experiência $\quad 36$

4.2. Variáveis Instrumentais $\quad 37$

4.3. Estimações com o Valor Presente do Contrato de Trabalho 39

4.3.1. Estatísticas Descritivas 39

4.3.2. Diferencial do VPCT com Controles 41

5 Conclusão 46

$\begin{array}{ll}6 \text { Referência Bibliográfica } & 47\end{array}$ 


\section{Lista de figuras}

Figura 1 - Histograma do Logaritmo do Rendimento Padronizado por Setor 18

Figura 2 - Salário Padronizado Médio 19

Figura 3 - Modelo Básico - Diferencial do Rendimento Padronizado Público Privado

Figura 4 - Oaxaca-Blinder - Diferencial do Rendimento Padronizado Público

Privado

Figura 5 - Modelo Básico - Diferencial do Rendimento Público Privado 35

Figura 6 - Oaxaca-Bliner - Diferencial do Rendimento Público Privado 35

Figura 7 - Histograma do Logaritmo do VPCT por Setor 40

Figura 8 - VPCT Médio 41

Figura 9 - Modelo Básico - Diferencial do VPCT Público Privado

Figura 10 - Oaxaca-Blinder - Diferencial do VPCT Público Privado 45 


\section{Lista de tabelas}

$\begin{array}{ll}\text { Tabela } 1 \text { - Composição da Força de Trabalho por Setor } & 17\end{array}$

Tabela 2 - Estatísticas do Rendimento Padronizado por Setor 18

Tabela 3 - Regimes Previdenciários $\quad 21$

Tabela 4 - Distribuição dos Regimes Previdenciários 21

Tabela 5 - Descrição das Variáveis $\quad 30$

Tabela 6 - Regressões com Rendimento Padronizado 31

Tabela 7 - Modelo de Interações entre Escolaridade e Experiência 37

Tabela 8 - Modelo com Variáveis Instrumentais 38

Tabela 9 - Estatísticas do VPCT por Setor $\quad 39$

Tabela 10 - Regressões com VPCT 43 